\title{
Trauma Surgery $\&$ Acute Care Open \\ Outcome in elderly patients with aortic stenosis undergoing hip fracture surgery. Results may suggest a different postoperative strategy?
}

\author{
Carlo Rostagno, ${ }^{1,2}$ Claudia Ranalli, ${ }^{2}$ Gianluca Polidori, ${ }^{2}$ Alessandro Cartei, ${ }^{2}$ \\ Alberto Boccaccini, ${ }^{3}$ Adriano Peris ${ }^{4}$
}

\begin{abstract}
'Dipartimento Medicina Sperimentale e Clinica, Università di Firenze, Firenze, Italy

${ }^{2} S O D$ Medicina Interna e Postchirurgica, AOU Careggi, Firenze, Italy

${ }^{3}$ SOD Anestesia e Rianimazione, AOU Careggi, Firenze, Italy ${ }^{4}$ Dipartimento

neuromuscoloscheletrico, AOU

Careggi, Firenze, Italy
\end{abstract}

Correspondence to Professor Carlo Rostagno, Department of Experimental and Clinical Medicine, University of Florence, Firenze 60127, Italy; carlo.rostagno@unifi.it

Received 28 July 2018 Revised 24 October 2018 Accepted 28 November 2018

(C) Author(s) (or their employer(s)) 2019. Re-use permitted under CC BY-NC. No commercial re-use. See rights and permissions. Published by BMJ.

To cite: Rostagno C, Ranalli C, Polidori G, et al. Trauma Surg Acute Care Open 2019:4:e000218.

\begin{abstract}
Background Five to ten percent of patients with hip fracture have severe aortic valve stenosis (AS). The aim of the present investigation was to evaluate the impact of AS on early and long-term outcome after surgery for hip fracture.

Methods 145 patients with AS and 283 consecutive patients without AS (control group) aged $>70$ years referred to Azienda Ospadaliera Universitaria (AOU) Careggi for hip fracture were included in the study. The endpoints were incidence of postoperative myocardial infarction, 30-day and 1-year mortality, and a composite endpoint (30-day mortality + myocardial infarction). Results 66 patients had mild, 47 moderate and 32 severe AS according to the European Society of Cardiology guidelines. 30 -day mortality was $6.2 \%$ in AS and $3.1 \%$ in controls. Postoperative non-fatal myocardial infarction and composite endpoint were more frequent in $\mathrm{AS}$ than in the control group ( $8.3 \%$ vs $1.1 \%, \mathrm{p}<0.001$ and $14.5 \%$ vs $4.2 \%, p<0.001$, respectively). The risk was significantly higher for patients with severe AS (28.1\%). 1-year mortality in patients with moderate/severe AS was $46 \%$ in comparison with $16 \%$ in mild AS or in the control group $(p<0.001)$. Coronary disease, atrial fibrillation, age, and aortic gradient were independent predictors of mortality in AS.

Discussion AS significantly affects postoperative outcome after surgery for hip fracture. Since not infrequently AS is incidentally diagnosed during hospitalization after trauma, which should be the management in these patients after hip surgery? How many might benefit from surgical valve replacement or transcatheter aortic valve replacement? A heart team evaluation may be suggested before discharge for most of these patients.

Level of evidence IV.
\end{abstract}

\section{INTRODUCTION}

In the elderly population, with the increased life expectancy, aortic stenosis (AS) has become the most frequent valve disease in Europe and North America. Data from the Euro Heart Survey suggest that moderate to severe degenerative calcific AS affects $2 \%$ to $3 \%$ of patients aged $>65$ years and $7 \%$ to $10 \%$ aged $>80$ years. $^{1}$

The need for non-cardiac surgery in patients with AS has increased significantly in the last two decades. AS is associated with a high risk of major cardiovascular events or death in the perioperative period. ${ }^{2}$ Guidelines suggest deferral of elective non-cardiac surgery after valve replacement. ${ }^{3} 4$ However, patients with untreated AS not rarely undergo non-cardiac surgery. The main reasons for non-adherence to the guidelines are asymptomatic cardiac status, refusal to valve replacement, urgency-emergency of non-cardiac surgery, and finally prohibitive risk from cardiac surgery related to multiple comorbidities. $^{5}$

Among the common urgent-emergent non-cardiac surgical procedures, hip fracture treatment has a prominent epidemiologic role. The incidence of severe AS in patients who need surgery for hip fracture is between 5\% and $10 \% .^{6}$ Although after hip surgery 30-day mortality in severe AS is between $7 \%$ and $14 \%,{ }^{7-9}$ these data may be an underestimate since the diagnosis of AS is not uncommonly missed before surgery. In fact only few centers have an echocardiography service that may allow assessment of AS severity without delaying surgery. Few retrospective studies $^{7-9}$ examined the prognostic role of AS on in-hospital and mid-term survival in this high-risk group of patients.

In January 2012, the Florence Trauma Centre created a multidisciplinary hip fracture unit to assess the preoperative risk, guide anesthesiology strategy, and direct postoperative management. ${ }^{10}$ The goal of this group was to stratify the risk before surgery, prevent and treat early complications, decrease perioperative mortality, and improve life expectancy and quality of life. The aim of the present investigation was to prospectively evaluate the impact of AS on early and long-term postoperative outcome in patients undergoing surgery for hip fracture referred to the Florence Hip Fracture Unit.

\section{METHODS}

The study is part of a project of the Italian Health Ministry and Regione Toscana (RF-2010-2316600). All patients gave written informed consent to treatment and collection of clinical data for research purposes at admission. The study was conducted according to the Strengthening the Reporting of Observational Studies in Epidemiology statements.

At hospital admission all consecutive patients with isolated hip fracture referred to the Florence Hip Fracture Unit underwent careful clinical evaluation to stratify surgical risk, allow scheduling of early surgery, and choose anesthesiology strategy. Functional status before surgery was assessed according to the Barthel Scale. ${ }^{11}$ The degree of cognitive impairment was assessed using the Short Portable 
Mental Status Questionnaire. ${ }^{12}$ Bedside transthoracic echocardiography was performed with a portable machine (Esaote MyLab V.40, Firenze). We measured left atrium diameter, left ventricle dimensions, and left ventricular ejection fraction (LVEF). The degree of mitral and aortic regurgitation was expressed as semiquantitative values. Peak and mean aortic valve gradients were measured by continuous Doppler. Aortic valve area (AVA) was calculated by continuity equation using velocity time integral (VTI). Severity of AS was defined according to the guidelines of the European Society of Cardiology ${ }^{13}$ : severe (AVA $<1 \mathrm{~cm}^{2}$ ), moderate (AVA 1-1.5 $\mathrm{cm}^{2}$ ), and mild (AVA $>1.5 \mathrm{~cm}^{2}$ ). Pulmonary systolic pressure was calculated adding right ventricle/right atrium (RV/RA) pressure gradient to the estimated right atrial pressure assessed by inferior vena cava diameter and response to respiratory acts.

ECG and laboratory examinations, including troponin I assay, were performed before and at 12, 24, and 48 hours after surgery. Deep venous thrombosis prophylaxis with low molecular heparin was started as soon as possible. Patients on chronic warfarin therapy were considered for drug withdrawal and oral vitamin $\mathrm{K}$ administration to recover normal clotting parameters. Perioperative diagnosis of acute myocardial infarction was made according to the criteria proposed by the Third Universal Definition of Myocardial Infarction. ${ }^{14}$ Follow-up was conducted as outpatient visits at 3 and 12 months after surgery.

\section{Statistical analysis}

Categorical variables are reported as frequency and percentage. Values for continuous variables were given as mean $( \pm S D)$. Categorical variables were compared using the $\chi^{2}$ test or the Fisher's exact test. Two-tailed Kaplan-Meier curves were used for survival analysis. Differences between groups were compared using log-rank test. After univariate analyses, a logistic multivariable regression analysis was performed to identify the independent predictors for mortality. Because of multiple testing, only variables with two-sided $\mathrm{p}<0.05$ in the univariate analysis were accepted in the model. Statistical analysis was performed using a statistical software program (SPSS version 22). A probability value of $<0.05$ was considered statistically significant.

\section{RESULTS}

The study enrolled 145 patients with hip fracture and AS confirmed on echocardiography before surgery and who were admitted to AOU Careggi between January 1, 2102 and June 30, 2015 (14\% of overall patients were referred for hip fracture in the whole period). Sixty-six (45.5\%) had mild AS, 47 (32.4\%) moderate AS, and 32 (22.1\%) severe AS. All patients referred for hip fracture between January 1, 2014 and June 31, 2014 underwent echocardiography at admission: 283 had no aortic valve disease and were considered as the control group of the present investigation. The clinical characteristics of patients with AS, stratified according to severity of valve disease, and the controls are reported in table 1 .

The groups did not differ in age and gender. In patients with AS, history of heart failure, coronary artery disease, and atrial fibrillation were significantly more frequent than in the controls. This was more evident in severe AS. Finally the presence of $\geq 2$ comorbidities was nearly twofold more common in patients with AS than in the controls $(65.5 \%$ vs $33.9 \%$; $\mathrm{p}<0.0001)$.

More relevant results of preoperative echocardiography are reported in table 2. Moderate to severe mitral regurgitation, higher values of systolic pulmonary pressure, and higher degree of left ventricular hypertrophy were more frequently associated with severe AS. LVEF was not significantly different between the three groups with AS and controls.

Surgery was performed within 48 hours from trauma in $75 \%$ of patients of the control group in comparison with $55 \%$ of the AS group, in whom the time to surgery was on average 12 hours longer. Since all patients underwent bedside echocardiography at the time of clinical evaluation for risk stratification, the delay to surgery was attributable only to the need for clinical stabilization or availability of intensive care unit (ICU) for postoperative monitoring.

Preoperative diagnosis of severe AS changed the anesthesiologist and clinical approach. In 90\% of patients with severe AS, surgery was performed under general anesthesia and arterial line was positioned for continuous hemodynamic monitoring. Fifty-six percent were scheduled for ICU monitoring in the 24

Table 1 Clinical features of patients with AS and the control group

\begin{tabular}{|c|c|c|c|c|c|}
\hline & $\begin{array}{l}\text { Mild AS } \\
\left(\text { AVA }>1.5 \mathrm{~cm}^{2}\right) \\
(66)\end{array}$ & $\begin{array}{l}\text { Moderate AS } \\
\text { (AVA } 1.0-1.5 \mathrm{~cm}^{2} \text { ) } \\
\text { (47) }\end{array}$ & $\begin{array}{l}\text { Severe AS } \\
\left(A V A<1.0 \mathrm{~cm}^{2}\right) \\
(32)\end{array}$ & $\begin{array}{l}\text { Control group } \\
\text { (283) }\end{array}$ & $P$ value \\
\hline Mean age, years & $84 \pm 7.5$ & $83 \pm 9.2$ & $87 \pm 5.8$ & $83 \pm 8$ & NS \\
\hline \multicolumn{6}{|l|}{ Fracture type, $n(\%)$} \\
\hline Femoral neck & $33(50)$ & $24(51.1)$ & $18(56.3)$ & $131(46.3)$ & NS \\
\hline Pertrochanteric & $31(47)$ & $20(42.6)$ & $14(43.7)$ & $136(48.1)$ & \\
\hline Intertrochanteric & $2(3)$ & $3(6.4)$ & 0 & $16(5.6)$ & \\
\hline Heart failure & $8(12.1)$ & $13(27.7)$ & $8(25)$ & $30(10.6)$ & 0.011 \\
\hline Renal insufficiency & $2(3)$ & $5(10.6)$ & $2(6.3)$ & $5(15.6)$ & 0.013 \\
\hline COPD & $4(6)$ & $9(19.1)$ & $3(9.4)$ & $28(10)$ & NS \\
\hline CAD & $17(25.8)$ & $12(25.5)$ & $5(15.6)$ & $41(14.4)$ & 0.023 \\
\hline $\begin{array}{l}\text { Atrial fibrillation } \\
\text { Arterial hypertension }\end{array}$ & $\begin{array}{l}15(22.7) \\
48(72)\end{array}$ & $\begin{array}{l}14(29.8) \\
35(74)\end{array}$ & $\begin{array}{l}13(40.6) \\
23(71)\end{array}$ & $\begin{array}{l}25(8.8) \\
215(75)\end{array}$ & $\begin{array}{l}<0.0001 \\
\text { NS }\end{array}$ \\
\hline $\mathrm{BADL} \leq 4$ & $43(65.2)$ & $33(70.2)$ & $13(40.6)$ & $75(26.5)$ & 0.002 \\
\hline Functional impairment & $11(16.7)$ & $28(38.3)$ & $14(43.8)$ & $127(44.9)$ & NS \\
\hline Parkinson's & $12(18.2)$ & $5(10.6)$ & $2(6.3)$ & $16(5.6)$ & 0.014 \\
\hline Cognitive impairment & $11(16.7)$ & $10(21.3)$ & $10(31.3)$ & 95 (33.6) & 0.009 \\
\hline
\end{tabular}

$A S$, aortic stenosis; $A V A$, aortic valve area; $B A D L$, basic activities of daily living; $C A D$, coronary artery disease; COPD, chronic obstructive pulmonary disease. 
Table 2 Preoperative echocardiographic parameters

\begin{tabular}{|c|c|c|c|c|c|}
\hline & $\begin{array}{l}\text { Mild AS } \\
\left(\text { AVA }>1.5 \mathrm{~cm}^{2}\right)\end{array}$ & $\begin{array}{l}\text { Moderate AS } \\
\left(\text { AVA } 1.0-1.5 \mathrm{~cm}^{2}\right)\end{array}$ & $\begin{array}{l}\text { Severe AS } \\
\left(\text { AVA }<1.0 \mathrm{~cm}^{2}\right)\end{array}$ & Controls & $P$ value \\
\hline $\begin{array}{l}\text { Peak aortic gradient, } \\
\text { mean } \pm S D\end{array}$ & $25.7 \pm 5$ & $47.1 \pm 10.1$ & $84.8 \pm 22.3$ & - & $<0.0001$ \\
\hline \multicolumn{6}{|c|}{ Aortic regurgitation, $\mathrm{n}(\%)$} \\
\hline Moderate & $6(9)$ & $17(36.1)$ & $17(53.1)$ & $36(12)$ & NS \\
\hline Severe & $1(1.5)$ & 7 (13.9) & $4(12.5)$ & $9(3.1)$ & \\
\hline \multicolumn{6}{|c|}{ Mitral regurgitation, $\mathrm{n}(\%)$} \\
\hline Moderate & $12(18.2)$ & $10(21.3)$ & $18(56.3)$ & $31(10)$ & $<0.05$ \\
\hline Severe & $1(1.5)$ & $4(8.5)$ & $7(21.9)$ & $10(4)$ & \\
\hline \multicolumn{6}{|l|}{ LVEF, n (\%) } \\
\hline$>55 \%$ & $51(77.3)$ & $40(85.1)$ & $23(71.9)$ & $231(82)$ & NS \\
\hline $36 \%-54 \%$ & $12(18.2)$ & $7(14.9)$ & 7 (21.9) & $52(18)$ & \\
\hline$<35 \%$ & $3(4.5)$ & 0 & $1(3.1)$ & & \\
\hline \multicolumn{6}{|c|}{ Systolic pulmonary artery pressure, $\mathrm{n}(\%)$} \\
\hline$<40 \mathrm{~mm} \mathrm{Hg}$ & $72(83.4)$ & $28(59.6 .6)$ & $20(62.5)$ & $182(65)$ & 0.0001 \\
\hline $40-60 \mathrm{~mm} \mathrm{Hg}$ & $8(12.1)$ & $16(34)$ & $9(28.1)$ & $98(34)$ & \\
\hline$>60 \mathrm{~mm} \mathrm{Hg}$ & $3(4.5)$ & $3(6.4)$ & $3(9.4)$ & $3(1)$ & \\
\hline LVH, n (\%) & $18(27.3)$ & $21(44.7)$ & $22(68.8)$ & $36(12)$ & 0.0005 \\
\hline
\end{tabular}

AS, aortic stenosis; AVA, aortic valve area; LEVF, left ventricular ejection fraction; LVH, left ventricular hypertrophy.

hours after the intervention. Only 5\% required ICU for hemodynamic instability.

According to the criteria reported in the Methods section, 12 patients with AS and 4 in the control group had postoperative myocardial infarction $(8.3 \%$ vs $1.1 \% ; \mathrm{p}<0.0001)$ (table 3$)$. None was fatal. The incidence of postoperative myocardial infarction showed a relation with the severity of AS $(15.6 \%$ in severe AS, $8.5 \%$ in moderate AS, and finally $4.5 \%$ in mild AS; $\mathrm{p}<0.0001$ ) (figure 1).

At 30 days overall mortality in patients with AS was $6.2 \%$ (9 of 145), twofold higher in comparison with the control group (3.1\%). Composite endpoint (30-day mortality + myocardial infarction) was found in $14.5 \%$ of patients with AS in comparison with $4.2 \%$ of the control group $(p=0.001)$. Incidence was significantly higher in patients with severe AS in comparison with moderate and mild AS (28.1\% in severe AS vs $10.6 \%$ in moderate and mild AS; $p=0.001$ ) (table 3 ). The length of hospital stay was not significantly different in patients with AS in comparison with the control group. Postoperative heart failure was significantly more frequent in patients with AS (15\% in patients with severe disease). Noteworthy, a higher incidence of postoperative delirium was found in patients with AS in comparison with the control group (29.7\% vs $19.8 \% ; p=0.0160)$ (table 4$)$.

One-year mortality was significantly higher in moderate/ severe AS in comparison with mild AS and control group $(46 \%, 16 \%$, and $18 \%$, respectively; $\mathrm{p}<0.001$ ) (figure 2 ). On multivariate analysis pre-existing coronary disease, atrial fibrillation, increasing age, and aortic gradient were independent predictors of mortality in patients with AS (table 5).

\section{DISCUSSION}

Among common urgent, or better time-dependent, non-cardiac surgery, hip fracture has a prominent epidemiologic role. In Italy, every year, not less than 90000 patients undergo surgery for hip fracture. ${ }^{15}$ Since the incidence of AS is between $5 \%$ and $10 \%$, it may be estimated that 4500 and 9000 patients with hip fracture suffer from severe AS. AS (average AVA of $0.97 \mathrm{~cm}^{2}$ ) was associated with a twofold increase of in-hospital mortality $(6.5 \%$ vs $3.2 \%$ ) in comparison with patients without AS. ${ }^{7}$

The Scottish Intercollegiate Guidelines Network guidelines in $2009^{16}$ suggested that echocardiography "should be performed if AS is suspected, to allow confirmation of diagnosis, risk stratification and any future cardiac management." However, they also state that the need for echocardiography "should not delay surgery unduly" and that if delays are to be avoided "rapid access to an echocardiography service is recommended." The cost of setting up and maintaining such a service may be offset by reducing delays and improving outcomes. Nevertheless, despite these recommendations, only a negligible proportion of patients with hip fracture undergo preoperative echocardiography, and the diagnosis of AS may be missed before surgery with an increase

Table 3 Clinical outcomes in patients with AS and controls

\begin{tabular}{|c|c|c|c|c|c|}
\hline & $\begin{array}{l}\text { Mild AS } \\
\left(\text { AVA }>1.5 \mathrm{~cm}^{2}\right)\end{array}$ & $\begin{array}{l}\text { Moderate AS } \\
\text { (AVA } 1.0-1.5 \mathrm{~cm}^{2} \text { ) }\end{array}$ & $\begin{array}{l}\text { Severe AS } \\
\left(\text { AVA }<1.0 \mathrm{~cm}^{2}\right)\end{array}$ & Control group & $P$ value \\
\hline 30-day mortality, n (\%) & $4(6)$ & $1(2.1)$ & $4(12.5)$ & $9(3.1)$ & 0.06 \\
\hline Myocardial infarction, n (\%) & $3(4.5)$ & $4(8.5)$ & $5(15.6)$ & $3(1.1)$ & 0.0001 \\
\hline 30-day mortality + AMI, n (\%) & $7(10.6)$ & $5(10.6)$ & $9(28.1)$ & $12(4.2)$ & 0.0001 \\
\hline Time to surgery (days) & $3.3 \pm 2.2$ & $2.8 \pm 1.9$ & $3.2 \pm 4.4$ & $2.6 \pm 1.64$ & 0.0001 \\
\hline LOS (days) & $15.9 \pm 7.0$ & $14.7 \pm 4.5$ & $15.7 \pm 7.6$ & $14.6 \pm 5.6$ & NS \\
\hline
\end{tabular}

$A M I$, acute myocardial infraction; $A S$, aortic stenosis; AVA, aortic valve area; LOS, length of hospitalization. 


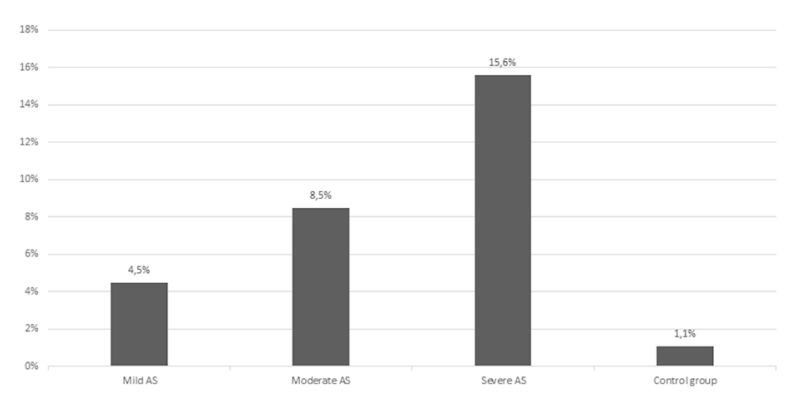

Figure 1 Incidence of postoperative myocardial infarction according to severity of aortic stenosis (AS) and in the control group.

in perioperative risk. In our study, physical examination revealed a systolic murmur in almost all patients with AS; however, only echocardiography allowed evaluation of the severity of aortic obstruction and choice of anesthesiology strategy to decrease perioperative risk. Twenty percent of patients with mild systolic murmur were found to have severe AS (valve area of $<1.0 \mathrm{~cm}^{2}$ ), thus leading to change in perioperative strategy.

In a retrospective case-control study by Keswani et al, ${ }^{8} 65$ subjects with AS and hip fracture were matched to 129 patients with hip fracture without aortic valve disease. Thirty-day and 1 -year mortality were significantly higher in the AS group $(14.7 \%$ vs $4.2 \%$ at 30 days and 46.8 vs $14.1 \%$ at 1 year). Moderate/ severe AS and chronic kidney disease were the only independent predictors of 1-year mortality. In the study of McBrien et $a l,{ }^{9} 272$ patients with hip fracture and previously undiagnosed AS were compared with 3698 patients with hip fracture and no AS. Patients with severe AS were more frequently treated under general anesthesia (66.7\%) and had arterial line positioning for continuous hemodynamic monitoring. Thirty-day mortality was $10 \%$ in severe AS in comparison with $6.25 \%$ in moderate AS and $7.4 \%$ in the control group, whereas 1 -year mortality in the three groups was $36,7 \%, 21.9 \%$, and $22.2 \%$, respectively. The authors reported that time from trauma to surgery was not significantly different in patients undergoing echocardiography for diagnosis of AS and in control patients (average 5 days).

The results of our prospective investigation confirm that in patients with hip fracture AS is associated with a 30-day, but in particular 1-year, poor outcome. Mortality at 30 days was slightly lower than previously reported. ${ }^{7-9}$ The different perioperative management (higher percentage of patients underwent

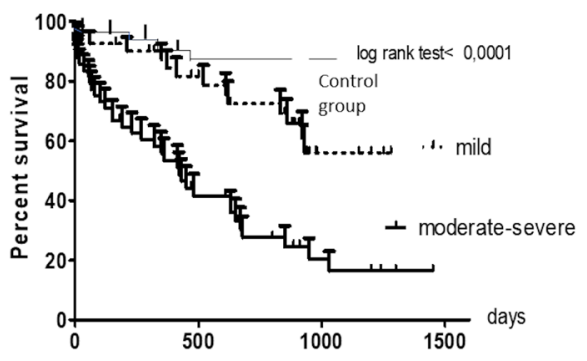

Figure 2 Kaplan-Meier survival curves in patients with moderatesevere AS, mild AS, and the control group. AS, aortic stenosis.

general anesthesia and were followed in ICU in the first 24 hours after surgery, the mean time to surgery was only 12 hours longer than in the controls) and the different clinical characteristics of populations under examination may explain these findings.

Postoperative myocardial infarction was significantly more frequent in patients with AS, in particular with severe disease; however, in our experience, none was fatal. Patients with valve disease had a more frequent history of coronary disease before trauma other than relevant left ventricular hypertrophy. It is likely that in these patients surgery-related hypotension (blood losses higher than expected, effects of anesthesia) may lead to inadequate coronary perfusion and to myocardial damage despite continuous hemodynamic monitoring and fluid management.

In patients with moderate/severe AS, mortality at 1 year is close to $50 \%$. Since in patients with hip fracture AS is not uncommonly diagnosed by chance during preoperative evaluation, a question that at present is without an answer is how these patients should be managed after hip surgery. Transcatheter aortic valve replacement (TAVR) is currently considered the standard of care for patients with severe AS who are considered at high prohibitive risk for surgical aortic valve replacement. ${ }^{17}$ Clinical characteristics in elderly patients with AS with or without hip fracture are not significantly different. ${ }^{18}$ Frailty is a common feature in patients with hip fracture; however, this condition is very prevalent (up to $80 \%$ ) also in patients undergoing TAVR. ${ }^{19} 20$ In our opinion referral to a "heart team" of patients with AS after hip surgery, which may not be delayed, might allow identification of those who may benefit from aortic valve replacement to improve long-term survival and quality of life. ${ }^{21}$ Only a large multicenter trial may have the number to verify this hypothesis.

Table 4 Postoperative complications, $\mathrm{n}(\%)$

\begin{tabular}{|c|c|c|c|c|c|}
\hline & $\begin{array}{l}\text { Mild AS } \\
\left(\text { AVA }>1.5 \mathrm{~cm}^{2}\right)\end{array}$ & $\begin{array}{l}\text { Moderate AS } \\
\text { (AVA 1.0-1.5 } \mathrm{cm}^{2} \text { ) }\end{array}$ & $\begin{array}{l}\text { Severe AS } \\
\left(\text { AVA }<1.0 \mathrm{~cm}^{2}\right)\end{array}$ & Control group & $P$ value \\
\hline RBC transfusion & $45(68.2)$ & $33(70.2)$ & $22(68.8)$ & $170(60)$ & NS \\
\hline Myocardial infarction & $3(4.5)$ & $4(8.5)$ & $5(15.6)$ & $3(1.1)$ & 0.0001 \\
\hline Sepsis & $1(1.5)$ & 0 & 0 & $5(1.8)$ & NS \\
\hline DVT & $4(6)$ & $4(8.5)$ & $2(6.3)$ & $15(5.3)$ & NS \\
\hline Stroke & 0 & 0 & 0 & $1(0.4)$ & NS \\
\hline Delirium & $16(24.2)$ & $18(38.3)$ & 9 (28.1) & $56(19.8)$ & 0.0160 \\
\hline Respiratory failure & $2(3)$ & 0 & $1(3.1)$ & $7(2.5)$ & NS \\
\hline Heart failure & $1(1.5)$ & $3(6.4)$ & $5(15.6)$ & $2(0.7)$ & 0.0001 \\
\hline $\mathrm{AF}$ & $2(3)$ & $1(2.1)$ & $1(3.1)$ & $3(1.1)$ & NS \\
\hline
\end{tabular}

$A F$, atrial fibrillation; $A S$, aortic stenosis; $A V A$, aortic valve area; $D V T$, deep venous thrombosis; $R B C$, red blood cell. 
Table 5 Predictors of 1-year mortality in patients with aortic stenosis

\begin{tabular}{|llll}
\hline & P value & OR & $95 \% \mathrm{Cl}$ \\
\hline Age & 0.0115 & 1.22 & 1.04 to 1.42 \\
\hline Time to surgery & 0.4695 & 0.98 & 0.93 to 1.03 \\
\hline Postoperative troponin I & 0.3951 & 1.14 & 0.84 to 1.54 \\
\hline Postoperative creatinine & 0.595 & 1.30 & 0.48 to 3.47 \\
\hline Pulmonary artery pressure & 0.6682 & 0.82 & 0.35 to 1.95 \\
\hline History of CAD & 0.0217 & 6.56 & 1.31 to 32.75 \\
\hline Atrial fibrillation & 0.0475 & 4.44 & 1.01 to 19.42 \\
\hline BADL & 0.935 & 0.98 & 0.68 to 1.41 \\
\hline Functional impairment & 0.0821 & 4.26 & 0.83 to 21.73 \\
\hline Mean aortic gradient (for $\mathrm{mm} \mathrm{Hg)}$ & $\mathbf{0 . 0 0 8 1}$ & $\mathbf{1 . 0 5}$ & $\mathbf{1 . 0 1}$ to 1.09 \\
\hline Mitral regurgitation & 0.3013 & 1.57 & 0.66 to 3.73 \\
\hline
\end{tabular}

Values in bold signify factors indepently related to 1-year mortality

$B A D L$, basic activities of daily living; $C A D$, coronary heart disease.

\section{CONCLUSION}

For patients with AS who need urgent non-cardiac surgery such as those with hip fracture, at present data are limited but suggest a significant overall mortality in comparison with patients without valve disease. AS in these patients is often previously undiagnosed, and only preoperative careful evaluation with echocardiographic examination may reveal its presence and severity. AS is usually associated with a higher risk of perioperative death and myocardial infarction. Preoperative detection of valve disease may lead to changing anesthesiologist strategy (from spinal to general anesthesia) and adoption of close hemodynamic monitoring that may limit perioperative complications, as suggested by the relatively low 30-day mortality in our study. Long-term prognosis in these patients treated with medical therapy, however, is poor. TAVR may therefore be a therapeutic option in selected patients. In our opinion referral to a "heart team" of patients with AS after surgery for hip fracture might allow identification of those who may benefit from aortic valve replacement to improve longterm survival and quality of life.

Contributors The conception and design of the study, acquisition of data, or analysis and interpretation of data $C R, A C$. Drafting the article or revising it critically for important intellectual content by $G P, C R, A C$ and final approval of the version to be submitted by $C R, A P, A B$.

Funding This study was funded by Ministero della Salute e Regione Toscana (RF2010-23166x)

Competing interests None declared.

Patient consent for publication Not required.

Ethics approval The study was approved by the Ministero della salute e Regione Toscana.

Provenance and peer review Not commissioned; externally peer reviewed.

Open access This is an open access article distributed in accordance with the Creative Commons Attribution Non Commercial (CC BY-NC 4.0) license, which permits others to distribute, remix, adapt, build upon this work non-commercially, and license their derivative works on different terms, provided the original work is properly cited, appropriate credit is given, any changes made indicated, and the use is non-commercial. See: http://creativecommons.org/licenses/by-nc/4.0

\section{REFERENCES}

1. lung $B$, Baron $G$, Butchart EG, Delahaye $F$, Gohlke-Bärwolf $C$, Levang OW, Tornos $P_{\text {, }}$ Vanoverschelde $J$, Vermeer $F$, Boersma $E$, et al. A prospective survey of patients with valvular heart disease in Europe: The Euro Heart Survey on Valvular Heart Disease. Eur Heart J 2003;24:1231-43.

2. Kertai MD, Bountioukos M, Boersma E, Bax JJ, Thomson IR, Sozzi F, Klein J, Roelandt $J R$, Poldermans D. Aortic stenosis: an underestimated risk factor for perioperative complications in patients undergoing noncardiac surgery. Am J Med 2004;116:8-13.

3. Fleisher LA, Fleischmann KE, Auerbach AD, Barnason SA, Beckman JA, Bozkurt B, Davila-Roman VG, Gerhard-Herman MD, Holly TA, Kane GC, et al. 2014 ACC/AHA guideline on perioperative cardiovascular evaluation and management of patients undergoing noncardiac surgery: a report of the American College of Cardiology/ American Heart Association Task Force on practice guidelines. J Am Coll Cardiol 2014;64:e77-137.

4. Kristensen SD, Knuuti J, Saraste A, Anker S, Bøtker HE, Hert SD, Ford I, GonzalezJuanatey JR, Gorenek B, Heyndrickx GR, et al. 2014 ESC/ESA Guidelines on noncardiac surgery: cardiovascular assessment and management: The Joint Task Force on non-cardiac surgery: cardiovascular assessment and management of the European Society of Cardiology (ESC) and the European Society of Anaesthesiology (ESA). Eur Heart J 2014;35:2383-431.

5. Agarwal S, Rajamanickam A, Bajaj NS, Griffin BP, Catacutan T, Svensson LG, Anabtawi AG, Tuzcu EM, Kapadia SR. Impact of aortic stenosis on postoperative outcomes after noncardiac surgeries. Circ Cardiovasc Qual Outcomes 2013;6:193-200.

6. Andersson C, Jørgensen ME, Martinsson A, Hansen PW, Gustav Smith J, Jensen PF, Gislason GH, Køber L, Torp-Pedersen C. Noncardiac surgery in patients with aortic stenosis: a contemporary study on outcomes in a matched sample from the Danish health care system. Clin Cardiol 2014;37:680-6.

7. Adunsky A, Kaplan A, Arad M, Mizrahi EH, Gottlieb S. Aortic stenosis in elderly hip fractured patients. Arch Gerontol Geriatr 2008;46:401-8.

8. Keswani A, Lovy A, Khalid M, Blaufarb I, Moucha C, Forsh D, Chen D. The effect of aortic stenosis on elderly hip fracture outcomes: A case control study. Injury 2016:47:413-8.

9. McBrien ME, Heyburn G, Stevenson M, McDonald S, Johnston NJ, Elliott JR, Beringer TR. Previously undiagnosed aortic stenosis revealed by auscultation in the hip fracture population--echocardiographic findings, management and outcome. Anaesthesia 2009:64:863-70.

10. Rostagno C, Cartei A, Buzzi R, Landi F, Gensini GF. Multidisciplinary Approach to Hip Fracture in the Elderly: Florence Experience. Open Access Emerg Med 2013;03:148.

11. Nanayakkara C, Lekamwasam S. Validity of the 5-item Barthel Index in the assessment of physical dependence in the elderly. Asian J Gerontol Geriatr 2015;10:79-82.

12. Pfeiffer E. A short portable mental status questionnaire for the assessment of organic brain deficit in elderly patients. J Am Geriatr Soc 1975;23:433-41.

13. Falk V, Baumgartner H, Bax JJ, De Bonis M, Hamm C, Holm PJ, lung B, Lancellotti P, Lansac E, Muñoz DR, et al. 2017 ESC/EACTS Guidelines for the management of valvular heart disease. Eur J Cardiothorac Surg 2017;52:616-64.

14. Thygesen K, Alpert JS, Jaffe AS, Simoons ML, Chaitman BR, White HD, Joint ESC/ACCF/ AHA/WHF Task Force for the Universal Definition of Myocardial Infarction, Katus HA, Lindahl B, Morrow DA, et al. Third universal definition of myocardial infarction. Circulation 2012;126:2020-35.

15. Piscitelli P, Brandi ML, Chitano G, Argentiero A, Neglia C, Distante A, Saturnino L, Tarantino U. Epidemiology of fragility fractures in Italy. Clin Cases Miner Bone Metab 2011:8:29-34

16. Scottish Intercollegiate Guidelines Network Management of hip fracture in older people A national clinical guideline. 2009. sign.ac.uk/pdf/sign 111.pdf.

17. Popma JJ, Adams DH, Reardon MJ, Yakubov SJ, Kleiman NS, Heimansohn D, Hermiller J, Hughes GC, Harrison JK, Coselli J, et al. Transcatheter aortic valve replacement using a self-expanding bioprosthesis in patients with severe aortic stenosis at extreme risk for surgery. J Am Coll Cardiol 2014;63:1972-81.

18. Thongprayoon C, Cheungpasitporn W, Kashani K. The impact of frailty on mortality after transcatheter aortic valve replacement. Ann Trans/ Med 2017;5:144.

19. Kaul S. Transcatheter aortic-valve replacement with a self-expanding prosthesis. $N$ Engl J Med 2014;371:967.

20. Finn M, Green P. Transcatheter aortic valve implantation in the elderly: who to refer? Prog Cardiovasc Dis 2014;57:215-25

21. Vahanian A, Alfieri O, Al-Attar N, Antunes M, Bax J, Cormier B, Cribier A, De Jaegere $P$, Fournial G, Kappetein AP, et al. Transcatheter valve implantation for patients with aortic stenosis: a position statement from the European Association of Cardio-Thoracic Surgery (EACTS) and the European Society of Cardiology (ESC), in collaboration with the European Association of Percutaneous Cardiovascular Interventions (EAPCI). Eur Heart J 2008;29:1463-70. 